Short Communication

\title{
IM PORTANCE OF BIRTH SPACING AMONG PRIMI POST NATAL MOTHERS
}

\author{
J. Karpagam ${ }^{1} \&$ D. Shangeetha ${ }^{2}$ \\ ${ }^{1}$ Nursing Superintendent, ${ }^{2}$ Nurse Educator, Department of M edical \& Surgical Nursing \\ PSG Hospitals, Peelamedu, Coimbatore - 641004 \\ Correpondence \\ J. Karpagam \\ Department of M edical \& Surgical Nursing, Nursing Superintendent, PSG Hospitals, \\ Peelamedu, Coimbatore - 641004. E-mail : karpagam_jambu @yahoo.co.in
}

\begin{abstract}
:
The study was conducted to evaluate the effectiveness of teaching programme for importance of birth spacing among primi post natal mothers. An evaluate approach with one group pre test post test design was used for the study. 60 samples were selected using purposive sampling method. The present study was conducted in PSG Hospitals Coimbatore.The collected data were

analyzed using descriptive and inferential statistics.A significant difference between pre test and post test knowledge was found ( $t$ $=27.94, p \varangle 0.05$ ). The study findings showed that educational programme has been an effective method of increasing the knowledge of the mothers. There was significant association between the level of knowledge and demographic variables such as age, educational status and type of family and there was no significant association between the level of knowledge and demographic variables such as religion and Occupation.
\end{abstract}

Keywords: Primi postnatal, Birth spacing.

\section{Introduction:}

Birth Spacing is important in child growth and development. The child is likely to receive his full share of love, care including nutrition needs, when the Family size is small \& births are properly spaced. Infants and mothers are extremely important part of the society as it lays the foundation for good nation. To achieve this it is necessary to improve the knowledge regarding child spacing. It is also well known that children born close together do not usually develop physically and mentally as well as children born three or more years apart. Birth spacing is the interval between births that provides the greatest health, social and economical benefits for family. Enabling couples to determine when they will have children is vital to safe motherhood and healthy children. Birth spacing refers to

\begin{tabular}{|c|}
\hline Access this article online \\
\hline Quick Response Code \\
\hline
\end{tabular}

mother and her children.

The study on birth spacing will be helpful for women to know their existing knowledge and also helpful for spouse and other members of the family because they will also be able to share and obtain the knowledge on birth spacing. The researcher is interested on this to pic because, M ost of the women do not make decision on family planning, their husbands take decision on family planning, contraceptive prevalence rate is also low in our country, and many women give birth within 24 months of previous birth.

\section{Need For The Study:}

An Indian women plays a vital role in contributing and preparing responsible citizen for the nation. The health of the women is an important component not only during reproductive years but also throughout the cause of her life. Women's health focus on the physical psychological and social needs, reproductive capacity of women plays an important role in helping them lives and health experiences. The ability to reproductive and regulate this fertility depends upon reproductive health. 
There may be very personal reasons why time is needed between pregnancies planning enough time between pregnancies increases the chance of a good outcome for the mother and each of her babies. If a parent has experienced a miscarriage or loss of a child, they may need time to grieve, evaluate their risks and work through their fears and anxieties before considering a future pregnancy. A couple or their child may have a medical condition which needs to be managed before they are able to begin or continue childrearing or a woman may be in her later reproductive years and be felling the need to have her pregnancies spaced closer together in order to achieve the family size she desires. A planned pregnancy is more likely to have a good outcome for the motherandbaby.

\section{Statement of The Problem}

"A STUDY ON EFFECTIVENESS OF STRUCTURED TEACHING PROGRAMME ON KNOWLEDGE REGARDING THE IMPORTANCE OF BIRTH SPACING AMONG PRIMI POST NATAL MOTHERS IN A SELECTED HOSPITAL AT COIM BATORE".

\section{Objectives}

- To analyze the socio-demographic profile of respondents.

- Assess the knowledge on birth spacing among primi post natal mothers as measured by using structured knowledge questionnaire.

- Find the association between the knowledge score of primi post natal mothers with selected demographic variables.

- To make suggestions based on the findings of the study.

\section{Materialsand M ethods:}

Research Design - The research design selected for the present study was descriptive in nature.

\section{Setting of the study:}

- Study will be conducted in the post natal ward department of a selected hospital at PSG Hospitals.

\section{Source of data collection}

The data will be collected from 60 primi post natal mothers admitted in the post natal ward of a selected hospital at Coimbatore, who fulfill the inclusion criteria.

\section{Population:}

- Population consists of all primi post natal mothers in a selected hospital at Coimbatore.

\section{Methodology:}

\section{Research design \& settings:}

One group pre test post test design which is a pre experimental design was adopted. The study was conducted in PSG Hospitals, Coimbatore.

Sampling Technique : Purposive sampling technique was used with 60

\section{Instrument}

Part 1: Demographic Performa

Part 2: A structured knowledge questionnaire will be developed to determine the knowledge of primi post natal mother on birth spacing.

Pre-test was administered to the participants who were admitted in the postnatal ward using structured knowledge questionnaire. The researcher collected the demographic data along with this. After pretest researcher conducted educational programme to the participants. After 7 days of intervention, the investigator administered the post test to assess the level of knowledge of mothers using the same structured knowledge questionnaire. The collected data were analyzed using descriptive and inferential statistics.

\section{Results and Discussion:}

\section{Findings related to socio demographic data}

- $61.6 \%$ (37) of mothers were in the age group of $21-25$ years, $38.4 \%$ (23) in the age group of $26-30$ years.

- $36.6 \%$ (22) comes under Hindu, 25\% (15) comes under Muslim, and $21.6 \%$ (13) comes under Christian.

- $43.3 \%$ (26) having primary education and $56.6 \%$ (34) having Diploma and above Education.

- $78.3 \%(47)$ of them come under non-working category 
and $21.6 \%$ (13) of the postnatal mothers were working.

- $38.3 \%$ (23) comes under joint family, $61.7 \%$ (37) comes under nuclear family.

\section{SECTION II: KNOWLEDGE OF PRIM I POST NATAL M OTHERS ON IM PORTANCE OF BIRTH SPACING:}

The data presented in the table 1 displays the frequency distribution of primi post natal mothers according to their pretest knowledge scores. The data showed that $36(60 \%)$ had poor knowledge score [score range 0-12], 11 (18.3\%) had average knowledge [score range 13-25], 13 (21.7\%) had good knowledge [score range 26-37] and according to their posttest knowledge score the data shows that $0 \%(0)$ had poor knowledge, 12 (20\%) had average knowledge, 48 (80\%) had good knowledge.

\section{SECTION III: EFFECTIVENESS OF AN EDUCATIONAL PROGRAMME}

The data shows that the mean post-test knowledge scores of primi post natal mothers were significantly higher than their mean pretest knowledge scorest (59) $=1.671$, and tab calculated value ' $t$ ' $=23.09 \mathrm{p} \varangle .05$ indicating there is significant difference pretest and post test knowledge scores. Hence research hypothesis $\mathrm{H} 1$ was accepted.

The primi post natal mothers were significantly higher mean score in post test than the mean pre-test. The analysis shows that the calculated value in all the areas are greater than the table value $(p \varangle 0.05)$.This shows that there was significant gain in the knowledge in all the areas of importance and methods of contraceptive methods. Therefore the educational programme has been an effective method of increasing the knowledge of the mothers.

Table 1 : 1Distribution of pretest and post test knowledge scores of the primi post natal mothers on importance of birth spacing

\begin{tabular}{|l|c|c|c|c|}
\hline Score Range & \multicolumn{2}{|c|}{ Frequency } & \multicolumn{2}{c|}{ Percentage } \\
\hline & pre test & Post test & pre test & Post test \\
\hline Poor (0-12) & 36 & 0 & 60 & 0 \\
\hline Average (13-25) & 11 & 12 & 18.3 & 20 \\
\hline Good (26-37) & 13 & 48 & 21.7 & 80 \\
\hline
\end{tabular}

Table : 2 M ean, Standard Deviation, ' $t$ ' value of pre test and post test

\begin{tabular}{|l|c|c|c|c|c|c|}
\hline Test & M ean & M ean & SD & Df & $\begin{array}{c}\text { 't' } \\
\text { value }\end{array}$ & $\begin{array}{c}\text { 'P' value } \\
\text { difference } \\
\text { (LOS) }\end{array}$ \\
\hline Pre test & 6.96 & 25.19 & 6.102 & 59 & 27.94 & $\begin{array}{c}0.000 \\
\text { P } \varangle .05 \\
\text { HS }\end{array}$ \\
\hline Post test & 32.15 & & & & & \\
\hline
\end{tabular}

Table 3 : Area-wise mean difference, standard deviation and't' value of pretest and posttest knowledge scores.

\begin{tabular}{|c|c|c|c|c|c|c|c|c|}
\hline \multirow[t]{2}{*}{$\begin{array}{l}\text { S. } \\
\text { NO }\end{array}$} & \multirow[t]{2}{*}{ Areas } & \multicolumn{2}{|c|}{$\begin{array}{c}\text { Mean knowledge } \\
\text { scores }\end{array}$} & \multirow[t]{2}{*}{$\begin{array}{c}\text { M ean } \\
\text { difference }\end{array}$} & \multirow[t]{2}{*}{ DF } & \multirow[t]{2}{*}{ SD } & \multirow[t]{2}{*}{$\begin{array}{c}\text { "t" } \\
\text { value }\end{array}$} & \multirow[t]{2}{*}{$\begin{array}{c}\text { "p" } \\
\text { value }\end{array}$} \\
\hline & & Pre test & Post test & & & & & \\
\hline 1 & Definition \& Importance & 1.70 & 4.92 & 3.22 & 59 & 1.20 & 16.87 & $\begin{array}{c}.000 \\
P \ll 0.05 \mathrm{HS}\end{array}$ \\
\hline 2 & Natural family planning & 3.92 & 7.05 & 3.12 & 59 & 1.82 & 10.81 & $\begin{array}{c}.000 \\
P<0.05 \mathrm{HS}\end{array}$ \\
\hline 3 & Barrier methods & 5.42 & 9.77 & 4.35 & 59 & 2.47 & 11.11 & $\begin{array}{c}.000 \\
P<0.05 \mathrm{HS}\end{array}$ \\
\hline 4 & Intrauterine Devices & 1.80 & 4.85 & 3.05 & 59 & 1.44 & 13.31 & $\begin{array}{c}.000 \\
P<0.05 \mathrm{HS}\end{array}$ \\
\hline 5 & Hormonal Method & 1.82 & 3.40 & 1.57 & 59 & 1.48 & 6.71 & $\begin{array}{c}.000 \\
P<0.05 \mathrm{HS}\end{array}$ \\
\hline 6 & $\begin{array}{l}\text { Emergency Contraceptive } \\
\text { M ethod }\end{array}$ & 0.16 & 0.95 & 0.79 & 59 & 0.45 & 13.35 & $\begin{array}{c}.000 \\
P<0.05 \mathrm{HS}\end{array}$ \\
\hline 7 & Injectable Steroids & 0.25 & 5.60 & 5.31 & 59 & 0.91 & 44.25 & $\begin{array}{c}.000 \\
P<0.05 \mathrm{HS}\end{array}$ \\
\hline
\end{tabular}


Figure 1: Percentage distribution of women according to their age

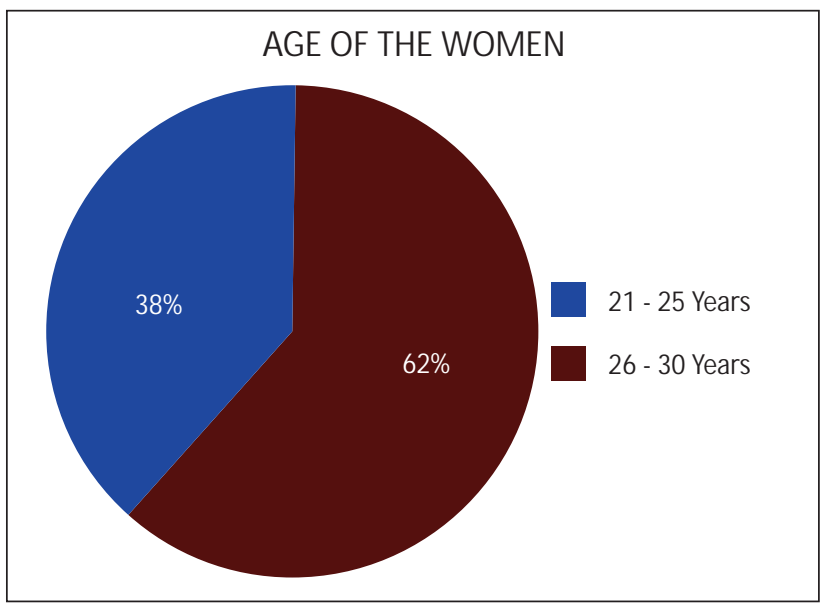

Figure 2: Percentage distribution of women according to their Religion

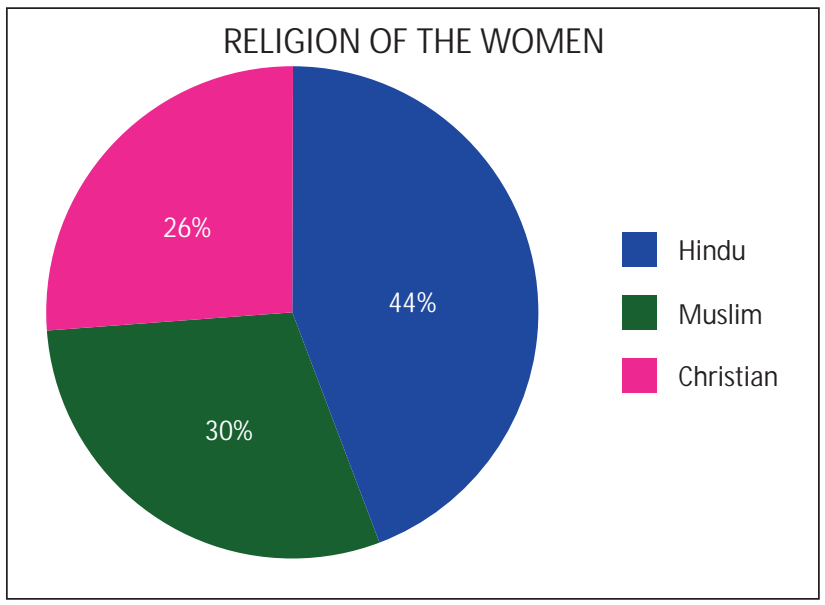

Figure 3: Percentage distribution of women according to their Educational Status

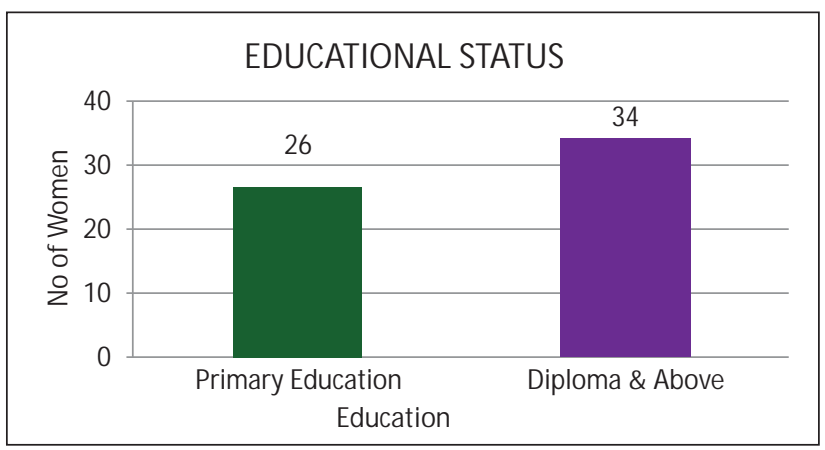

Figure 4: Percentage distribution of women according to their Occupational Status

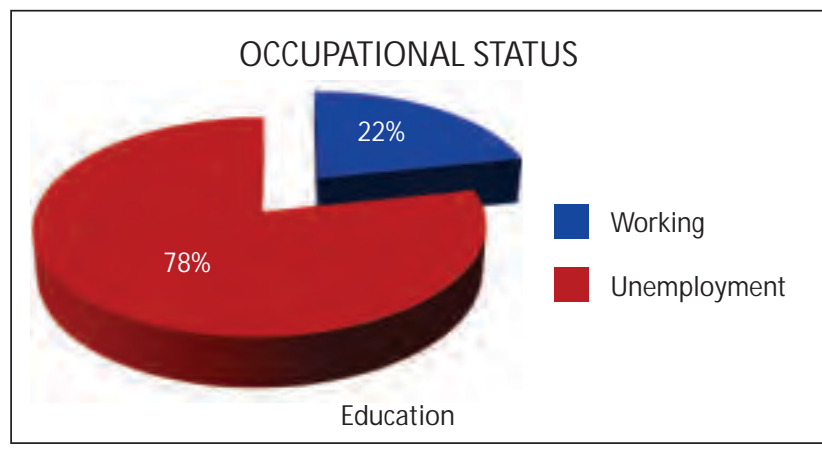

Figure 5: Distribution of women according to their Type of Family

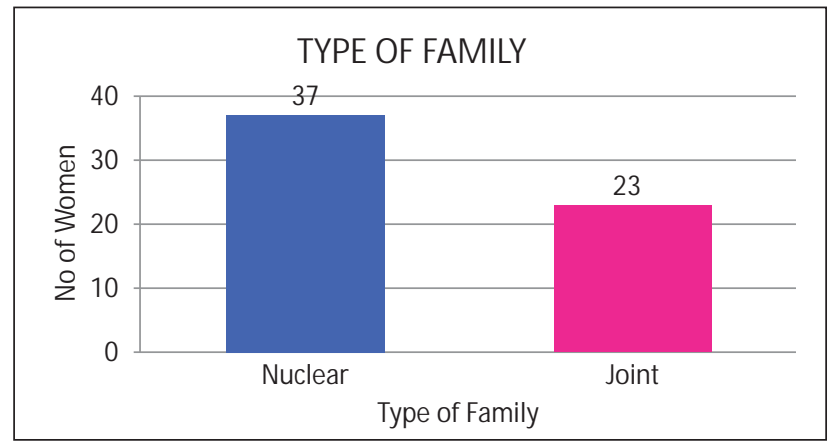

\section{SECTION IV : ASSOCIATION BETWEEN THE KNOWLEDGE} SCORE OF PRIMI POST NATAL MOTHERS WITH SELECTED

\section{DEM OGRAPHICVARIABLES}

Chi square value for association between the knowledge level and selected demographic variables like education (ccal =6.046), age (ccal =8.750) and Type of Family (ccal = 6.6) were greater than table value at 0.05 level of significance. Hence research hypothesis $\mathrm{H} 2$ was accepted. Chi square value for association between the knowledge level and selected demographic variables like religion (ccal $=1.55$ ), occupation (ccal $=0.011$ ) were less than table value at 0.05 level of significance. Hence research hypothesis $\mathrm{H} 2$ was rejected.

\section{Conclusion:}

In this study a structured teaching programme was given to primi post natal mothers and its effectiveness was evaluated. The data presented indicate that the post test mean percentage knowledge scores in all content areas were higher than the pretest mean percentage knowledge scores. The modified mean percentage score is also good in 
all the areas and which shows the educational programme was effective. The nurses play a key role in patient care from the day of admission to the day of discharge; nurse is with the patient, caring and consoling. So, the nurse is expected to give nursing care as well as health teaching regarding importance of birth spacing and contraceptive

\section{References:}

1. Alan,E ,(2007), International Family Planning Perspectives Vol.23 No (1) :62-65

2. Bunce, A., et al. (2007) International Family Planning Perspectives 33(1): 13-21.

3. Sarah B. Family planning advice and postpartum contraceptive use among low income women in M exico. International Family Planning Perspectives (March 2007); 33(1): pp. 6-12. Available from: URL: http://www.jstor.org/pss/30039187

4. Caltabiano, M.and, Castiglioni,M., (2008) International Family Planning Perspectives, 34(1):30-39.

5. Health day News, (2006) "Researchers seek optimal pregnancy interval."

6. International Family Planning Perspectives (1997) V0I.23 (2)

7. Sharma, E., Pandey, R., Abdulla,H.,(2008), Journal of Tropical Pediatrics: Birth Interval and Risk of Still birth or Neonatal Death 10: 1093

8. Stubble field, G (2007) "Inter pregnancy interval and pregnancy outcome."

9. DH survey analysis. A lack of knowledge about methods and source of contraceptives, 1999

10. Nirmala sapkota, Rebecca sinha, Radha Devi. Knowledge and attitude on birth spacing among reproductive age among married women. Indian Journal of obstetrics and gynecology(2008), 60(6) 585-593. methods and it can be better understood by the patients, family members and the community at large.

\section{Acknowledgement:}

We are extremely thankful to staffs of post natal ward, PSG Hospitals, Coimbatore for their kind help and assistance in collecting data from mothers. 